DOI: http://dx.doi.org/10.18764/2358-4319.v10n1p101-124

\title{
O processo de construção e aprovação do plano de carreira dos profissionais do magistério da rede estadual de ensino do estado do Pará
}

\author{
Denielson Moura Ferreira ${ }^{1}$ \\ Dalva Valente Guimarães Gutierres ${ }^{2}$ \\ Ana Paula da Silva Carneiro ${ }^{3}$
}

\section{RESUMO}

O estudo tem como objetivo discutir o processo de construção e aprovação da Lei no 7.442/2010 que dispõe sobre o Plano de Cargos, Carreira e Remuneração - PCCR - dos profissionais do magistério da rede estadual de ensino do Estado do Pará. Como metodologia utilizou-se a pesquisa bibliográfica e documental. Foram analisadas as propostas do governo para o Plano de Carreira e as proposições do sindicato de professores constantes em informativos sindicais e jornais da época que originaram a Lei $n^{\circ} 7.442 / 2010$. O estudo evidenciou que o processo de construção e aprovação da Lei n 7.442/2010 foi marcado por conflitos entre governo e sindicato de professores. As diversas mobilizações, passeatas e greves de professores durante o processo possibilitaram alterações significativas na política de carreira proposta pelo governo, o que favoreceu a inclusão de propostas oriundas da representação do magistério público estadual.

Palavras-Chave: Plano de Carreira; Valorização do Magistério Público; Carreira do Magistério.

1 Mestre em Educação pela Universidade Federal do Pará (UFPA). Professor. Técnico em Educação da Secretaria Estadual de Educação do Pará (SEDUC). E-mail: denielsonmoura5@ hotmail.com/

2 Doutora em Educação pela Universidade Federal do Rio Grande do Sul (UFRGS). Professora do curso de Pedagogia e do Programa de Pós-Graduação em Educação da Universidade Federal do Pará (UFPA). E-mail: dalva.valente@gmail.com

3 Mestranda em Educação pela Universidade Federal do Pará (UFPA). Técnica em Educação da Secretaria Municipal de Educação do Município de Belém (SEMEC).E-mail: pauladscarneiro@ gmail.com 


\title{
The making and approval process of the career plan of teaching professionals of Pará's education network
}

\begin{abstract}
This study's goal is to discuss the making and approval process of Law no. 7.442/2010, which defines the Offices, Career and Remuneration Plan - PCCR - of teaching professionals of Pará State's education network. It was employed book and file research as methodology. Were analyzed the government's proposals towards PCCR and the propositions of the teachers'labor union commonly found in papers and syndicate newsletters of the time Law no. 7.442/2010 was originated. The study shows that the whole process of making and approval of Law no. 7.442/2010 which was marked by conflicts between state and the teachers' labor union. Various mobilizations, rallies and strikes along the process allowed significant changes in the career policy proposed by the government, which enabled inclusion of proposals from the state public teaching body.
\end{abstract}

Keywords: Career Plan; Appreciation of Public Teaching; Teaching Career.

\section{El proceso de construcción y aprobación del plan de carrera de profesionales de la Enseñanza de la red estatal de educación del estado de Pará}

\section{RESUMEN}

El estudio tiene como objetivo analizar el proceso de construcción y aprobación de la Ley № 7.442 / 2010, que prevé el Plan de Carrera, Carrera y Remuneración - PCCR -. Metodología de la enseñanza profesional del estado de la educación del estado de Pará Tal como se usa el documental y bibliográfico. las propuestas del gobierno se analizaron para el Plan de Carrera y las propuestas del sindicato maestros constantes en boletines y periódicos de la época que dio lugar a la Ley № 7.442 / 2010 del sindicato. El estudio demostró que el proceso de construcción y aprobación de la Ley № 7.442 / 2010 estuvo marcado por el conflicto entre el gobierno y el sindicato de maestros. Las protestas, marchas y varias huelgas de los maestros durante el proceso habilitadas cambios significativos en la política de carrera propuesto por el gobierno, lo que favoreció la inclusión de propuestas de la representación de la enseñanza pública del estado.

Palabras clave: plan de carrera; la apreciación pública del Magisterio; carrera magisterial. 


\section{Introdução}

Este artigo tem como tema o Plano de Carreira do Magistério da Educação Básica e é parte dos resultados de uma dissertação de mestrado. $\mathrm{O}$ artigo tem como objetivo discutir o processo de construção e aprovação do Plano de Cargos, Carreira e Remuneração - PCCR dos profissionais do magistério da rede estadual de ensino do Estado do Pará. Com o estudo buscamos responder às seguintes questões: como ocorreu o processo de construção do PCCR dos profissionais do magistério da educação básica da rede estadual de ensino do Estado do Pará? Quais as propostas do governo e do sindicato de professores nesse processo? Como metodologia utilizou-se a pesquisa bibliográfica e documental. As propostas do governo do Estado e as proposições do sindicato de professores para o Plano de Carreira foram analisadas a partir de informativos governamentais, sindicais e jornais da época.

O artigo se apresenta estruturado em três seções: a primeira enfatiza a política de carreira do magistério público como instrumento de valorização dos profissionais da educação, prevista na legislação brasileira; a segunda intitulada "O Processo de Construção do Plano de Cargos, Carreira e Remuneração - PCCR/2010" e a terceira denominada "O processo de aprovação do Plano de Cargos, Carreira e Remuneração - PCCR" destacam o processo conflitivo de construção e de aprovação do PCCR da rede estadual de ensino do Pará respectivamente, considerando o papel assumido pelo Sindicato dos Trabalhadores em Educação Pública do Estado do Pará - SINTEPP diante da proposta governamental. Por fim, as considerações finais trazem algumas reflexões, buscando responder aos questionamentos que motivaram o estudo.

\section{A política de carreira do magistério público no contexto da legislação brasileira}

Com o propósito de construir uma educação pública de qualidade para todos, na década de 1980 a questão da valorização docente foi muito debatida por movimentos de professores, o que resultou na aprovação do art. 206, inciso V da CF/1988, que definiu como um dos princípios do ensino: 
Valorização dos profissionais do ensino, garantido na forma da lei, plano de carreira para o magistério público, com piso salarial e ingresso exclusivamente por concurso público de provas e títulos, assegurado regime jurídico único para todas as instituições mantidas pela União (BRASIL, 1988, grifos nossos)

Percebemos a exigência de plano de carreira como uma das formas de garantir valorização aos profissionais do ensino público. No entanto, essa exigência não foi cumprida pelas redes públicas de ensino, o que fez com que na década de 1990 as lutas dos educadores se intensificassem pelo cumprimento constitucional de garantia de planos de carreira e também por melhorias salariais, como forma de garantir a atratividades da profissão do magistério às novas gerações (ROCHA, 2009).

A Lei de Diretrizes e Bases da Educação Nacional - LDB n. 9.394/1996 - em seu art. 67 assegura que a valorização dos profissionais da educação pública deve ser garantida pelos sistemas de ensino por meio de Estatuto e de Plano de Carreira para o Magistério Público, nos quais deverão estar assegurados o ingresso na carreira exclusivamente por concurso público de provas e títulos; a formação continuada com licenciamento remunerado; o piso salarial; a progressão funcional; o período reservado a estudos, planejamento e avaliação, incluído na carga de trabalho; e condições adequadas de trabalho.

Nessa perspectiva foi criada a Lei no. 9.424/1996 que instituiu o Fundo de Manutenção e Desenvolvimento do Ensino Fundamental e de Valorização dos Profissionais do Magistério - FUNDEF - (que vigorou por um período de 10 anos), substituído pelo Fundo de Manutenção e Desenvolvimento da Educação Básica e de Valorização dos Profissionais da Educação - FUNDEB - por meio da Lei no. 11.494/2007.

O FUNDEF, por ser voltado especificamente para o Ensino Fundamental, propôs em seu art. $7^{\circ}$ a aplicação de no mínimo $60 \%$ dos seus recursos para pagamento de professores desse nível de ensino. Além disso, estabeleceu que no prazo de 6 (seis) meses, ou seja, de julho de 1997 a janeiro de 1998, os Estados, o Distrito Federal e os Municípios deveriam dispor de Plano de Carreira e Remuneração do Magistério, assegurando a remuneração condigna dos professores do Ensino Fundamental público, em efetivo exercício no magistério; estímulo ao trabalho em sala de aula; e a melhoria da qualidade do ensino (art. $9^{\circ}$, 
incisos I, II e III). Entretanto, em relação à remuneração dos professores, a Lei no. 9.424/1996 (FUNDEF) nada especificou, deixando para os Estados e os Municípios definirem regras a esse respeito em seus Planos de Carreira. A Lei do FUNDEF definiu que deveriam ser criadas diretrizes de carreira (art. $9^{\circ}$ e 10 ${ }^{\circ}$. Assim, de acordo com Dutra Jr (2000), em abril de 1996 o Ministério da Educação - MEC - enviou à Câmara de Educação Básica (CEB) do Conselho Nacional de Educação (CNE) uma proposta de Diretrizes Nacionais para subsidiar a elaboração dos novos Planos de Carreira e Remuneração do Magistério Público, que deram origem à Resolução nº. 03/1997 - CEB/CNE. Essa Resolução fixou as diretrizes para os novos Planos de Carreira e de Remuneração para o Magistério dos Estados, do Distrito Federal e dos Municípios, mas eram diretrizes restritas aos profissionais do Magistério do Ensino Fundamental.

Com a criação do Fundo de Manutenção e Desenvolvimento da Educação Básica e de Valorização dos Profissionais da Educação FUNDEB pela EC. nº. 53/2006, regulamentado pela Lei no. 11.494/2007, passou-se a atender toda a educação básica. Assim, foi estabelecido que no mínimo $60 \%$ de seus recursos devessem ser destinados para pagamento dos profissionais da educação básica (art. 22). Esta mesma lei estabeleceu em seu art. 40 o que os entes federados elaborassem os seus Planos de Carreira de modo assegurar remuneração condigna aos profissionais da educação básica e melhoria da qualidade do ensino. A lei de regulamentação do FUNDEB também determinou prazo para a provação de lei específica de criação do piso salarial profissional para o magistério, fixado em "até 31 de agosto de 2007" (Art. 41). Mas tal prazo não foi cumprido, pois somente em 2008 mediante a aprovação da Lei no. 11.738/2008 foi instituído o Piso Salarial Profissional Nacional - PSPN, adotado como política pública no governo Lula.

De acordo com a Lei no. 11.738/2008 (Lei do PSPN), o piso salarial é o valor abaixo do qual os entes federados não podem fixar o vencimento inicial dos profissionais do magistério da educação básica, em início de carreira para jornada de, no máximo 40 (quarenta) horas semanais, ou seja, nenhum profissional do magistério da educação básica pública pode ter seu vencimento abaixo do valor fixado para o piso salarial, que deve ser reajustado anualmente. O valor do PSPN estipulado se destina aos professores com formação de nível médio na modalidade normal para uma jornada de 40 horas semanais; $1 / 3$ da composição 
da jornada do professor destina-se à hora-atividade (BRASIL, 2008), ou seja, as atividades extraclasse. Vale mencionar que a definição do valor do piso a cada ano não impede os sistemas de ensino de reajustarem o vencimento dos profissionais do magistério com um valor superior ao definido pelo governo federal. É importante destacar que sobre o valor do PSPN incidem as gratificações.

A Lei do Piso estabeleceu novo prazo (até 31 de dezembro de 2009) para que a União, os Estados, o Distrito Federal e os Municípios elaborassem ou adequassem seus Planos de Carreira e Remuneração dos Profissionais do Magistério Público (art. 6). Com a Lei do FUNDEB e do PSPN ocorreram mudanças que ensejaram novas diretrizes de Plano de Carreira para o Magistério Público, que foram aprovadas por meio da Resolução nº 02 de 28 de maio de 2009. Essas novas diretrizes para os Planos de Carreira e Remuneração dos Profissionais do Magistério da Educação Básica Pública consideram o que já havia sido estabelecido na CF/88, na LDB/96 e na Lei no. 11.494/2007 a respeito da necessidade de que os entes federados elaborassem ou adequassem seus Planos de Carreira de acordo com a legislação vigente.

As Diretrizes Nacionais para os Planos de Carreira e Remuneração dos Profissionais do Magistério da Educação Básica Pública ampliam o conceito de profissionais ${ }^{4}$ do Magistério da Educação Básica, considerando os que desempenham as atividades de docência ou aqueles que dão suporte pedagógico à docência. Em relação à jornada de trabalho, diferentemente da Resolução n. 3/96 que fixava o percentual entre $20 \%$ e $25 \%$ do total da jornada para hora atividade, a Resolução 02/09 não determina percentual e sugere jornada de trabalho preferencialmente em tempo integral de no máximo 40 (quarenta) horas semanais, com possibilidade de ampliação paulatina da jornada destinada à hora atividade, assegurando-se no mínimo os percentuais da jornada que já vêm sendo destinados para esta finalidade pelos diferentes sistemas de ensino, de acordo com os respectivos projetos político-pedagógicos (art. 4º, inciso VII).

4 Aqueles que desempenham as atividades de docência ou as de suporte pedagógico à docência: direção ou administração, planejamento, inspeção, supervisão, orientação e coordenação pedagógica, exercidas no âmbito das unidades escolares de educação básica, em suas diversas etapas e modalidades (Educação Infantil, Ensino Fundamental, Ensino Médio, Educação de Jovens e Adultos, Educação Especial, Educação Profissional, Educação Indígena) (art. $2^{\circ}, \$ 1^{\circ}$ da Resolução 02/2009), com a formação mínima determinada pela LDB nº. 9.394/1996 
A mera existência de leis definindo a necessidade de formulação e/ou reformulação e implantação dos Planos de Carreira para o Magistério, embora importantes, não tem sido suficiente para que isso se concretize. Sobre isso, Abreu (2011, p.01) nos informa que:

\begin{abstract}
Entre os planos de carreira do magistério das 27 Ufs, 4 são anteriores à LDB/1996; 16 foram elaborados entre a LDB e o FUNDEF, em 1996. Dos 5.532 municípios, apenas $43 \%$ declararam ao MEC possuir planos de carreira implementados para seus profissionais do magistério.
\end{abstract}

Isso indica que, a despeito do que recomendam as legislações quando se referem à valorização do magistério por meio da criação de Planos de Carreira, tais recomendações não vinham sendo atendidas pela maioria dos municípios. De acordo com Abreu (2011), o percentual de municípios que possui plano de carreira do magistério implementado é insuficiente, sendo apenas de 43\% dos 5.532 municípios pesquisados. Isso corrobora o descumprimento de legislações no Brasil e a persistência da valorização do magistério público apenas no papel.

O Plano Nacional de Educação - PNE (2014-2024) ou Lei nº. 13.005/2014 constitui outro importante instrumento que orienta a execução de políticas educacionais. No que diz respeito à carreira, em sua a meta 18 o PNE estabelece o seguinte:

Assegurar, no prazo, de 2 (dois) anos, a existência de planos de Carreira para os profissionais da educação básica pública de todos os sistemas de ensino, tomando como referência o piso salarial nacional profissional, definido em lei federal, nos termos do inciso VIII do art. 206 da CF/1988.

De acordo com a meta 18 estabeleceu-se o prazo até junho de 2016 para que as redes públicas de ensino elaborassem ou reelaborassem seus Planos de Carreira. Certamente essa meta ainda não foi cumprida. Além disso, as redes públicas de educação básica precisariam assegurar até o início do terceiro ano de vigência do PNE (em 2017) que no mínimo $90 \%$ dos profissionais do magistério e que 50\% no mínimo dos profissionais da educação, não docentes, fossem concursados e estivessem recebendo o valor do PSPN (Lei no 13.005/2014). 
Em sua estratégia 18.4, o PNE estabelece que os entes federados devam prever em seus Planos de Carreira "licenças remuneradas e incentivos para qualificação profissional, inclusive em nível de pósgraduação stricto sensu". Assim, a licença remunerada durante os cursos de mestrado e doutorado torna-se um importante incentivo e deverá constar nos Planos de Carreira para a formação continuada e para a elevação da qualidade da educação básica pública no Brasil.

O cumprimento da legislação brasileira, no que se refere à implementação dos planos de carreira, pelos sistemas de ensino, exige que os professores e as entidades que os representam continuem suas lutas reivindicatórias por implementação de políticas públicas que visem à consolidação da valorização do magistério como ponto central, nas reformas educacionais, atuando no resgate do papel social do professor.

\section{O processo de construção do Plano de Cargos, Carreira e Remuneração - Pccr/2010}

Desde a Constituição Federal de 1988 que o Plano de Carreira do magistério foi estabelecido como um dos instrumentos principais de valorização dos profissionais da educação escolar. Porém, até 2010, a rede estadual de ensino do Pará não dispunha de PCCR, sendo que a carreira dos profissionais do magistério estadual era regida pela Lei $\mathrm{n}^{\circ}$. $5.351 / 186$, que instituiu o Estatuto do Magistério Estadual do Pará, e pela Lei no. 5.810/1994, que trata do Regime Jurídico Único dos Servidores Públicos Civis da Administração Direta, das Autarquias e das Fundações Públicas do Estado do Pará, ou simplesmente, Estatuto dos Servidores (BRELAZ, 2010).

A necessidade de um Plano de Carreira que garantisse direitos, tais como ingresso na carreira via concurso público de provas e títulos; remuneração digna; progressão funcional; período reservado a estudos, planejamento e avaliação incluídos na carga horária de trabalho; estímulo à formação; e condições adequadas de trabalho com possibilidade de dedicação exclusiva em um único estabelecimento de ensino levou os professores paraenses a lutar por melhores condições de trabalho e de carreira.

Nessa perspectiva, no período entre 2007 a 2010, durante o Governo Popular de Ana Júlia Carepa (PT), o governo estadual e os 
representantes do Sindicato de Trabalhadores da Educação Pública do Pará - SINTEPP começaram a debater a construção do Plano de Cargos. Por se tratar de "Governo Popular", os trabalhadores da educação a possibilidade de avanços significativos no desenvolvimento da carreira.

Esse processo foi acompanhado de greves, manifestações, passeatas e debates pela aprovação de um PCCR unificado, em que todos os profissionais da educação básica da rede estadual fossem contemplados.

Para dar consequência a essa reivindicação, em 2008 foi instituída uma comissão para a elaboração do Plano de Cargos, Carreira e Remuneração, constituída por dez (10) membros para a instalação da Mesa Permanente de Negociações, de caráter paritário, sendo cinco (05) representantes da SEDUC e cinco (05) do SINTEPP (Portaria n 049/2008 - GAB/SEC) (OLIVEIRA apud COELHO, 2009) a se reunir uma vez a cada mês para debater os problemas e assim tentar encontrar uma solução (ASCOM/SEDUC, 14/08/2008).

Em 10 de março de 2009, reuniram-se representantes do SINTEPP e do governo do Estado para discutir a Campanha Salarial de 20095, quando foi anunciado que a mesa permanente de negociação seria composta por representantes de mais quatro secretarias ${ }^{6}$ : Secretaria de Estado de Planejamento, Orçamento e Finanças (SEPOF), Secretaria da Fazenda (SEFA), Centro Integrado de Governo (CIG), Casa Civil e Secretaria de Governo (SEGOV) (ASCOM/SEDUC, 10/03/2009).

A composição da mesa denegociação ampliada pode demonstrar o alargamento do espaço democrático de debates e diálogos. Contudo, tal concepção não se refletia no discurso dos Secretários Adjuntos de Logística e de Gestão da SEDUC ao afirmarem em junho de 2009 que o PCCR seria definido a partir da perspectiva do governo e não de propostas entre o governo do Estado e o Sindicato, visto que "[...] as perspectivas do SINTEPP vão [iam] além das possibilidades financeiras e dos limites legais", pois pelas propostas do sindicato, o impacto que o PCCR causaria

5 Esta reunião contou com a presença de Roberto Sena, representante do Departamento Intersindical de Estatísticas e Estudos Socioeconômicos (DIEESE) e dos Secretários Adjuntos de Ensino, Socorro Brasil, e de Logística, Ely Benevides, além do coordenador de Lotação da SEDUC, Teodomiro Sanches Neto

6 A incorporação de outros membros à mesa de negociação ocorreu pela necessidade de mais esclarecimentos a respeito de questões financeiras, reivindicados pelos membros do sindicato, e que ficavam sem resposta por falta de conhecimento dos representantes da SEDUC. 
na folha de pagamento da SEDUC, no ano de 2009 seria em torno de $\mathrm{R} \$ 68$ milhões de reais (ALEPA, 25/06/2009), quantitativo que alegavam ser elevado. $O$ posicionamento dos secretários contradizia o discurso do governo que se dizia democrático e participativo. A mesa de negociação constituída em 2008 foi modificada durante os três anos e meio de elaboração do PCCR. Após o governo prometer várias vezes enviar o Plano de Carreira à Assembleia legislativa e não cumprir os prazos, em 2009 ocorreu uma greve que durou mais de 40 dias, que entre outras reivindicações pleiteava a criação do PCCR. (DIÁRIO ON LINE, 2009)

A proposta de PCCR do Governo do Estado do Pará só foi apresentada no dia 28 de abril de 2010, no auditório da Escola Estadual Tecnológica Anísio Teixeira, aos gestores das Unidades SEDUC na Escola (USEs) e Unidades Regionais de Educação (UREs) (ASCOM/SEDUC, 29/04/2010). Essa mesma proposta foi apresentada para aproximadamente 600 diretores de escolas, professores e técnicos da rede estadual de ensino no dia 04 de maio de 2010. Nesse encontro, os servidores presentes passaram a conhecer o documento e debater sobre questões importantes como piso salarial, jornada, avaliação de desempenho, entre outros, muitas delas, Ihes pareceram obscuras (ASCOM/SEDUC, 04/05/2010). Por não concordarem com o Projeto de PCCR, os professores reuniram-se em assembleia geral no dia 07 de abril de 2010, e após análise do documento votaram pelo indicativo de greve para o dia 07 de maio de 2010, movimento que se estendeu até o dia 04 de junho daquele ano (SINTEPP, 2010). A avaliação pelos coordenadores do SINTEPP e que motivou a greve era de que o projeto de PCCR apresentado pelo governo do Estado alterava substancialmente as propostas discutidas anteriormente pelos membros do SINTEPP e pelos representantes do governo do Estado em mesa de negociação.

Durante o período da greve, tanto os representantes do sindicato, como os do governo intensificaram as discussões sobre a importância do Plano de Carreira para a categoria, e após alguns encontros de negociação com os coordenadores do SINTEPP e em assembleia com professores, no dia 07 de maio de 2010, foi protocolado novamente pelo governo na Assembleia Legislativa o Plano com as alterações, modificações e supressões apresentadas pelos representantes dos profissionais do magistério público paraense. 
Durante o período da greve, o primeiro questionamento dos representantes do Sindicato à proposta de PCCR do executivo estadual foi em relação ao título "Plano de Cargos, Carreira e Remuneração do Magistério Público da Educação Básica da Rede Pública de Ensino do Estado do Pará". Para os coordenadores do SINTEPP, com esse título o Plano incluía apenas os integrantes do grupo do magistério, isto é, professores e técnicos em educação. E como a proposta dos membros do Sindicato era de um Plano unificado, eles propuseram a substituição dos termos "magistério público da educação básica" por "trabalhadores da educação básica". Este título corresponderia, na visão dos dirigentes sindicais, a todos os profissionais que desenvolvem suas atividades nas escolas (professores, técnicos e aqueles que desenvolvem funções administrativas, como assistente educacional e auxiliar educacional, além dos operacionais). De acordo com os cálculos dos coordenadores do Sindicato, pela proposta de Plano de Carreira do governo estadual de contemplar apenas professores e técnicos, "dos 60 mil trabalhadores da educação na rede estadual de ensino, seriam excluídos cerca de 14 mil servidores de escolas" (SINTEPP, 2010). Para os dirigentes do Sindicato dos professores, não havia necessidade de o técnico em educação constituir-se em um cargo específico, uma vez que, esse profissional já é considerado como docente, pois desenvolve atividade pedagógica ou de suporte pedagógico, por isso, deveria ser incluído no cargo de professor, e assim seria criado apenas esse cargo. E a garantia de cargo único de professor que contemplasse tanto os que atuam em sala de aula como os de função técnica chegou a ser apresentada pelos representantes do SINTEPP aos membros do governo do Estado nas mesas de negociação.

Os representantes do sindicato chegaram a propor a criação do cargo de assistente operacional educacional, que comportaria outros trabalhadores que nunca foram contemplados pelo Estatuto do Magistério/1986, como secretários, merendeiras, porteiros, entre outros cargos técnicos de nível médio e assistente operacional de educação (ASCOM/SEDUC, 31/03/2009). Diante do que se debateu e se acatou nas mesas de negociações e do que foi encaminhado pelo executivo estadual e aprovado pela Assembleia

A não abrangência de todos os trabalhadores da educação na proposta do executivo estadual teve duas justificativas pelos 
representantes da SEDUC: em virtude do proposto pela Lei $\mathrm{n}^{\circ}$. $11.738 / 2008$ (Lei do PSPN) que definia quem eram os profissionais da educação, que para o governo seriam os professores e os técnicos em educação; e pela questão orçamentária da SEDUC, que já destinava $80 \%$ ( $\mathrm{R} \$ 82$ milhões de reais) de seus recursos financeiros para o pagamento da folha de pessoal da educação, e não garantia condições de cumprimento orçamentário para um plano de abrangência de todos os trabalhadores da educação como defendiam os dirigentes do Sindicato (DIÁRIO DO PARÁ, 27/05/2010).

Por entender que trabalhadores em educação são todos os profissionais que atuam nas escolas, independentemente da função que exercem, a proposta dos representantes do sindicato era que se acrescentassem os termos "trabalhadores da educação" e "docência", mas a proposta aprovada apresenta no Parágrafo único do art. $4^{\circ}$ somente $o$ conceito de "trabalhadores em educação". Esta foi mais uma proposta dos coordenadores do sindicato que não foi considerada pelo governo do Estado, caso contrário, o PCCR seria inclusivo e unificado, como os dirigentes do sindicato defendem.

No que se refere ao aspecto estrutural da carreira, os representanres do SINTEPP propuseram que a carreira possuísse 5 (cinco) classes (Classe I, II, III, IV e V) sem a Classe Especial. Porém, na proposta do governo, a Classe Especial constitui a primeira. Talvez pelo fato de a escolaridade exigida para esse cargo ser apenas a formação do ensino médio, na modalidade normal, o governo o excluiu da carreira, considerando-o cargo em extinção.

Em relação à movimentação na carreira, para os membros do Sindicato, a progressão funcional deveria conter quinze (15) níveis, representados pelas letras de " $\mathrm{A}$ " a " $\mathrm{O}$ ", e a evolução seria de forma automática a cada dois (2) anos (biênio), diferente da proposta do governo que apresentava 12 (doze) níveis definidos de " $A$ " a "L" com evolução a cada três (3) anos (triênio). A proposta do governo prevaleceu na Lei aprovada.

Outro ponto de divergência entre os dirigentes sindicais e o governo do Estado foi devido à proposta do executivo não permitir a progressão vertical aos professores AD-1 e AD-2 (correspondentes à Classe Especial) ${ }^{7}$ ou seja, o professor com formação de nível médio, ao

7 Os professores AD1 e AD2 de acordo com o Estatuto do Magistério correspondem aos 
concluir o ensino superior estaria impedido pela proposta do governo do Estado de ascender mediante sua nova habilitação ou escolaridade. $\mathrm{O}$ documento do governo só permitia que esses professores ascendessem de forma horizontal $\left(\operatorname{art} .14 \S 1^{\circ}\right.$ ), ou seja, por tempo de serviço e avaliação de desempenho.

Ao propor a não existência da Classe Especial na estrutura da carreira, os representantes do Sindicato defendiam que os profissionais com requisitos correspondentes à Classe Especial deveriam pertencer à Classe I, deixando de ser "especial" e passariam a ter o direito de serem promovidos a partir da formação de nível superior. Porém, na lei aprovada, esta proposta não foi aceita. Contudo, caso consigam habilitarse em curso de licenciatura plena, Ihes foi garantida, na lei, uma vantagem pecuniária progressiva de $10 \%$ até o limite de $50 \%$ no final da carreira.

A progressão vertical foi condicionada à disponibilidade orçamentária e em casos de limitação do número de vagas, seriam utilizados critérios de seleção dos candidatos inscritos para a garantia de progressão. Esses critérios são: a) produção acadêmica; b) produção bibliográfica; c) atuação em missões institucionais; d) participação em eventos científicos; e e) participação em programas de formação e/ ou qualificação profissional relacionada à educação (art. 17). Pelo fato de vincular ou condicionar a progressão vertical à disponibilidade orçamentária, os representantes do SINTEPP solicitaram a supressão dos art. 17 e 22, que estabelecia que o processo de avaliação da categoria fosse de responsabilidade do Poder Executivo. Porém, na lei aprovada foi mantida a proposta do governo. Isso significa que a progressão está diretamente vinculada à questão orçamentária.

Trata-se de critérios pessoais que os docentes precisam garantir por conta própria para obter a progressão vertical. Consiste em política de meritocracia, o que não consideramos como fator positivo para a melhoria da valorização docente, pois os critérios precisam ser ofertados ou garantidos pelo próprio Estado e não unicamente pelo servidor. Essa situação tende a fortalecer a disputa entre os próprios professores e a se distanciar do reconhecimento e da isonomia profissional.

No que se refere à progressão funcional horizontal (Art. $15 \S 1^{\circ}$ e $2^{\circ}$ ), o governo propôs que para sua efetivação o servidor precisaria

professores com formação de magistério modalidade Normal e professores com Estudos Adicionais.

Revista Educação e Emancipação, São Luís, v. 10, n. 1, jan./abr. 2017 
solicitá-la junto à Comissão Permanente de Avaliação de Desempenho Funcional. Entretanto, para conceder, a Comissão deveria considerar os seguintes critérios: a) assiduidade; b) pontualidade; c) participação efetiva nas atividades de elaboração da proposta político-pedagógica e de planejamento pedagógico da escola; d) aplicação dos princípios e das práticas previstas na proposta pedagógica; e) produção em cursos de formação que permeia a área da Educação Básica; f) eficiência; g) responsabilidade; h) cumprimento de metas (art. 10). Estes são aspectos de responsabilidade individual do servidor e relacionados à intensificação do trabalho.

A Lei aprovada trouxe esses itens alterados em relação à garantia de avaliação não apenas dos profissionais da educação, mas também do sistema de ensino, pois para os dirigentes do sindicato, o sistema precisa ser avaliado no que se refere à garantia de condições de trabalho e de valorização do magistério, haja vista que em função da ausência desse tipo de garantia, o governo poderá atribuir boa parte de sua responsabilidade pelo processo educativo, aos professores. Diante disso, cabe uma interrogação: que condições os poderes públicos têm oferecido aos docentes para a melhoria da qualidade do ensino?

Ainda no art. $15, \S 2^{\circ}$ da proposta do Governo, a progressão horizontal fica condicionada à disponibilidade orçamentária limitando assim, o número de progressões horizontais. E para isso, seriam aplicadas regras de desempate, tais como: I - conceito atribuído pela Comissão Permanente de Avaliação de Desempenho Funcional; II - maior tempo de serviço na carreira; III - maior tempo de serviço na classe; IV - maior tempo de serviço no nível; $\mathrm{V}$ - maior idade. Ao avaliar a proposta, os dirigentes do Sindicato divergiram e solicitaram a retirada da proposta mencionada nos parágrafos $1^{\circ} \mathrm{e} 2^{\circ}$ do art. 15 , por compreenderem que a garantia da progressão deveria ser automática para todos os profissionais da educação, mediante o cumprimento dos pré-requisitos necessários e de obrigação do governo estadual. Para os coordenadores do SINTEPP, esses requisitos de avaliação defendidos pelo governo do Estado configuram uma perspectiva punitiva, classificatória, ranqueadora e meritocrática. Para os sindicalistas a avaliação precisa ocorrer numa perspectiva formativa, diagnóstica, democrática e universal (SINTEPP, 2010). 
Devido a Classe Especial corresponder ao que o Estatuto denominou de AD1, AD2 e AD3, e por isso estar fora da carreira proposta pelo PCCR, a política salarial dos professores seria a partir da Classe I. $O$ vencimento de uma classe posterior seria o equivalente ao valor do vencimento da classe anterior, nível $A$, acrescido de 1,5\%.

A coordenação do Sindicato propôs que fossem alterados os vencimentos iniciais apresentados pela proposta do governo para os cargos a partir do Nível A, da Classe l, da seguinte forma: do Nível I: Professor de Nível Médio; Nível II: Professor Licenciado Pleno - 10\% (dez por cento) a mais que o Nível l; Nível III: Professor Especialista - 50\% (cinquenta por cento) a mais do que o Nível Il; Nível IV: Professor Mestre 20\% (vinte por cento) a mais do que o Nível III; Nível IV: Professor Doutor - $10 \%$ (dez por cento) a mais que o Nível IV. ${ }^{8}$

A diferença de remuneração5 entre os níveis, no caso de progressão horizontal seria, conforme a proposta do sindicato, de $5 \%$ (cinco por cento) do vencimento do Nível A da respectiva Classe e não de $0,5 \%$ (zero vírgula cinco pontos percentuais) como defendia o governo. No entanto, este artigo não foi modificado, tendo prevalecido assim à proposta do executivo estadual, o que aumentou a insatisfação e a indignação dos professores ao tomar conhecimento das denúncias de escândalos de irregularidades envolvendo a SEDUC, com licitações indevidas, serviços não executados, pagamentos de produtos não entregues e superfaturamento. Isso dificultou ainda mais ao governo convencer a categoria do magistério de que não havia recursos financeiros para viabilizar o PCCR proposto pelo Sindicato (RIBEIRO, ABEL, SINTEPP, 2010).

Ainda sobre o aspecto da remuneração, vale destacarmos que em dezembro de 2009 os representantes do SINTEPP entregaram aos deputados estaduais na ALEPA uma proposta de projeto de PCCR que "Dispõe sobre a Carreira dos Trabalhadores da Educação Básica do Estado do Pará" solicitando apoio dos parlamentares na negociação com o governo para fazer valer a proposta do sindicato (SINTEPP, 2009). Por essa proposta, o valor do Piso Salarial era de:

8 Constituída pela somatória de todos os pagamentos devidos (salário ou vencimento, $13^{\circ}$ salário proporcional, $1 / 3$ de adicional de férias, férias vencidas, proporcionais ou antecipadas gratificações, horas extras, aviso prévio, gratificações ou retribuições pelo exercício do cargo ou função de direção ou chefia, salário família, etc) ao profissional do Magistério, e dos encargos sociais (Previdência Social e FGTS) devidas pelo empregador, correspondente à remuneração paga com esses recursos aos profissionais do Magistério em efetivo exercício [...] (FUNDEF, 2004, Lei do RJU; DUTRA JR, 2000, p. 215). 
I - O Piso Salarial do professor com nível médio será de $\mathrm{R} \$ 2.005,07$ (dois mil cinco reais e sete centavos);

II - O Piso Salarial do professor licenciado pleno será de $\mathrm{R} \$$ 4.010,14 (quatro mil dez reais e quatorze centavos);

III - O Piso Salarial do professor especialista será de R\$ $6.015,21$ (seis mil quinze reais e vinte e um centavos);

IV - O Piso Salarial do professor mestre será de R\$ $7.218,25$ (sete mil duzentos e dezoito reais e vinte e cinco centavos);

V - O Piso Salarial do professor doutor será de R\$ 8.020, 28 (oito mil vinte reais e vinte e oito centavos);

VI - O Piso Salarial do auxiliar educacional será de R\$ 930,00 (novecentos e trinta reais);

VII - O Piso Salarial do assistente educacional será de $\mathrm{R} \$ 2.005,07$ (dois mil, cinco reais e sete centavos) (SINTEPP, 2009).

Porém, a proposta salarial da lei aprovada não foi a prevista pelos dirigentes do Sindicato. De acordo com representantes da SEDUC, com a proposta do PCCR aprovado, os professores da rede estadual de ensino teriam um aumento de até $30 \%$ (trinta por cento) em seus salários.

Para os representantes do Sindicato, a proposta da SEDUC acarretaria perda salarial de $\mathrm{R} \$ 224,19$ (duzentos e vinte e quatro reais e dezenove centavos) aos professores.

A direção do SINTEPP defendeu que fosse incluído no art. 29 da proposta do governo a concessão de gratificação no valor de $50 \%$ (cinquenta por cento) do piso para os trabalhadores em educação que desenvolvem suas atividades na Superintendência do Sistema Penal (SUSIPE) e na Fundação da Criança e do Adolescente (FUNCAP) por se tratar de locais considerados como de risco de vida e no Sistema Modular de Ensino (SOME)6 por se tratar de um projeto que atende alunos em vários municípios do Estado. Essa proposta do sindicato foi incorporada ao Plano, mas precisaria de lei específica para regulamentá-la.

Quanto ao regime de trabalho para o cargo de professor, o projeto de PCCR do governo instituiu jornada em regência de classe de 20, 30 e 40 horas semanais. Dessa jornada, 20\% (vinte por cento) seriam 
para a ${ }^{9}$ hora-atividade (planejamento, correção e formulação de provas, participação em reuniões pedagógicas, entre outros, (art. 31, § $2^{\circ}$ ). Pela proposta dos dirigentes do Sindicato, a hora-atividade equivaleria no mínimo a 1/3 (um terço) da jornada de trabalho do professor, como prevê a Lei do Piso Salarial.

No art. $31 \S 3^{\circ}$ de sua proposta, o governo previa que o professor que não estivesse em sala de aula tivesse sua jornada de trabalho de 30 horas semanais. Para os dirigentes do SINTEPP, essa proposta representa redução na jornada do professor em 10 horas e, consequentemente, em seu salário. Sobre a jornada do profissional que não estivesse em regência de classe, pelo art. 32 da proposta do governo, deveria se considerar a disponibilidade de carga horária e a opção do professor. Proposta também questionada pelos dirigentes do SINTEPP por compreendêla como mantenedora do professor horista a exemplo de como ocorre atualmente. Esses pontos foram solicitados pelos sindicalistas que fossem retirados da Lei.

Pelo argumento do governo, a aplicação da Lei do PCCR dependeria das despesas decorrentes da dotação orçamentária proveniente do FUNDEB, o que também foi sugerido sua retirada pelos dirigentes sindicais. Para estes, até o ano de 2010 o governo estadual já tinha reduzido para 20\% (vinte por cento) os investimentos em educação, contrariando o dispositivo da CF/1988 que estabelece que o Estado deva investir no mínimo $25 \%$ (vinte e cinco por cento) de sua arrecadação total de impostos em manutenção e desenvolvimento do ensino - MDE (SINTEPP, 2010; CF/1988).

Em síntese, para os dirigentes do SINTEPP, o Plano de Cargos, Carreira e Remuneração proposto pelo governo não estabelecia o Piso Salarial, não contemplava toda a categoria, não beneficiava o professor com nível médio na progressão vertical, não assegurava de fato a progressão horizontal e o percentual estabelecido para esta era de apenas 0,5\% (zero vírgula cinco por cento) (SINTEPP, 2010). No entanto, todas essas propostas foram aprovadas.

96 O SOME é um projeto especial implantado em 1980, pela Fundação Educacional do Pará (FEP), mantido pela SEDUC a partir de 1982. Sua finalidade consiste em ofertar o Ensino Fundamental, de $5^{\mathrm{a}}$ a $8^{\mathrm{a}}$ séries e Ensino Médio, para alunos dos municípios e localidades do interior do Estado em que as carências estruturais, em especial, a ausência de material humano qualificado, impossibilitem em curto prazo, a oferta e manutenção do ensino regular (BRELAZ, 2010). 


\title{
O processo de aprovação do Plano de Cargos, Carreira e Remuneração - PCCR
}

No dia 06 de maio de 2010 o PCCR foi encaminhado à Assembleia Legislativa do Pará (ALEPA) pela própria governadora e protocolado pela SEPOF em 07 de maio daquele ano, sob o número 86/2010 (ASCOM/ SEDUC, 08/05/2010). É preciso lembrar que o prazo estabelecido pelo art. $6^{\circ}$ da Lei n. 11.738/2008 - PSPN - há muito havia passado.

Ao projeto enviado à ALEPA foi anexada a mensagem de $n^{\circ}$. 86/2010, constando a seguinte declaração da governadora:

\begin{abstract}
O PCCR se apresenta como um conjunto de normas que irá, a partir de promulgada esta lei, disciplinar o desenvolvimento do servidor na carreira correlacionando cargos e níveis de escolaridade. O Plano proporciona o aperfeiçoamento profissional, remuneração digna, reconhece a importância da carreira para a oferta de um ensino público e de qualidade à população paraense.
\end{abstract}

Destaco ainda que, o Plano apresenta aos servidores do Magistério progressão horizontal e vertical dando a possibilidade de formação continuada [...] (PARÁ, 2010).

Mesmo com a mensagem da governadora enfatizando a valorização docente da rede estadual de ensino do Pará, para Brelaz (2010), assessor jurídico do SINTEPP, o PCCR encaminhado pelo executivo à ALEPA, não configurou aquilo que a categoria desejava, pois não contemplou alguns direitos e garantias fundamentais para a carreira docente.

O Projeto de Lei $n^{\circ}$. 086/2010 foi apreciado no dia 09 de junho de 2010 e sofreu algumas modificações em reuniões conjuntas nas Comissões de Constituição e Justiça (CCJ), Fiscalização Financeira e Orçamentária (CFFO), Comissão de Educação da ALEPA. Foram feitas 14 (quatorze) emendas, sendo 8 (oito) aditivas, 2 (duas) supressivas e 4 (quatro) modificativas. A partir de então, a denominação "Plano de Cargos, Carreira e Remuneração do Magistério da Educação Básica da Rede Estadual de Ensino do Estado do Pará - PCCR" foi substituída por "Plano de Cargos, Carreira e Remuneração dos Profissionais da Educação Básica da Rede Pública de Ensino do Estado do Pará - PCCR" (SINTEPP, 2010; ASCOM/SEDUC, 2010). 
Após mais de um mês de tramitação, com passeatas, protestos e reuniões, em 15 de junho de 2010 em Sessão Ordinária e por unanimidade pelos deputados da ALEPA foi aprovado o Projeto de Lei no. 86/2010, que "dispõe sobre o Plano de Cargos, Carreira e Remuneração dos Profissionais da Educação Básica da Rede Pública de Ensino do Estado do Pará e dá outras providências" - PCCR. Entre os 31 deputados presentes na Sessão para a aprovação do projeto, não houve discordância por parte de nenhum parlamentar, e assim o projeto foi aprovado com todas as emendas acordadas entre o Governo do Estado e o Sindicato, intermediada por parlamentares (ASCOM/SEDUC, 16/06/2010), transformando-se na Lei no. 7.442/2010, no dia 02 de julho de 2010, sendo assinada pela governadora Ana Júlia, no dia de 13 de julho do mesmo ano, após 24 anos do Estatuto do Magistério/1986.

Os docentes reivindicavam um Plano de Carreira que regulamentasse inclusive todos os profissionais da educação da rede estadual de ensino. Sobre essa inclusão de todos os profissionais da educação do sistema estadual de ensino, merecem ser enfatizadas as propostas apresentadas pelos coordenadores do SINTEPP que foram incorporadas e aprovadas pela ALEPA:

[...] a inclusão dos cargos de auxiliar educacional e assistente educacional como trabalhadores em educação, concretizando a unificação do Plano; gratificação SOME; gratificação de risco de vida e alta complexidade; gratificação ao professor de nível médio; jornada de trabalho a ser cumprida, prioritariamente, numa única unidade de ensino; efetivação das horas-atividade de $20 \%$ para $25 \%$ sobre a jornada de trabaIho, com a majoração deste percentual para $25 \%$ até 2014; retirada de critérios subjetivos na avaliação de desempenho; garantia de progressão horizontal no prazo de um ano e pagamento retroativo, em caso de indisponibilidade financeira devidamente comprovada, bem como, instituição da progressão automática; equiparação do cargo de especialista em educação ao cargo de professor em jornadas de trabalhos e vencimentos (BRELAZ, 2010, p. 6-7).

Pela proposta de Plano de Carreira defendida pela CNTE e pelo SINTEPP, o PCCR/2010 deve se configurar em um conjunto de normas que regulamentem o ingresso de todos os profissionais da educação, o desenvolvimento do servidor na carreira, que corre- 
lacione as classes de cargos com os níveis de escolaridade e de remuneração dos servidores e estabeleça critérios para o desenvolvimento mediante progressão vertical e horizontal (PARÁ, 2010, art. 4º, inciso I).

Neste sentido, surge a seguinte inquietação: as propostas apresentadas pelo SINTEPP durante o processo de construção do PCCR dos profissionais do magistério público estadual e aquelas aprovadas e transformadas em Lei se configuram em propostas de efetiva valorização para a carreira do magistério estadual do Estado do Pará?

\section{Considerações finais}

O estudo nos permitiu compreender que o processo de luta dos professores em defesa da educação pública de qualidade tem se intensificado no sentido da implementação de políticas de valorização dos profissionais do magistério, como preconiza a Constituição Federal de 1988, com a instituição de Planos de Carreira, haja vista que é o Plano de Carreira que estabelece o aperfeiçoamento profissional e continuado aos professores, melhorando seu desempenho profissional e a remuneração.

Ficou evidente também que um Plano que priorize a formação e a melhoria salarial, e consequentemente, da educação, ocasiona impacto financeiro na folha de pagamento, no caso do Estado do Pará; mas, por outro lado, precisa ser compreendido pelo Estado como investimento em educação e que contribuirá para a melhoria da qualidade do trabalho docente e da valorização dos professores e da educação e, em consequência, da educação como um todo.

O estudo nos possibilitou compreender que no Estado do Pará a carreira do magistério público no período de 1987 a 2010 esteve regulamentada pelo Estatuto do Magistério - Lei no. 5.351/1986 e a partir de 2011, a regulamentação passou a ser feita pelo Plano de Cargos, Carreira e Remuneração - Lei no. 7.442 - PCCR/2010. Além de alguns direitos dos docentes estabelecidos no Estatuto/1986 não terem sido efetivados, a construção do PCCR/2010 se deu por conta de novas legislações das décadas de 1990 e 2000 que tratam de carreira do magistério, como é o caso da LDB/1996, da Lei no. 11.494/2007 (FUNDEB), Lei no. 11.738/2008 (Piso Salarial Profissional Nacional - PSPN), da Resolução 02/2009 (CEB/ CNE) e da Lei 13.005/2014 (Plano Nacional de Educação - PNE). 
Outro aspecto evidenciado no estudo foi a expectativa criada pelos profissionais do magistério em relação ao governo de Ana Júlia (PT). Pela composição política de seu governo foram tantas as contradições em relação às concepções políticas de um Governo Popular e as ações efetivadas, como por exemplo, no que se refere às propostas para a construção do PCCR/2010. Mesmo as propostas tendo sido discutidas coletivamente entre integrantes do governo do Estado e do sindicato representante dos professores, no momento da aprovação do Plano prevaleceram várias propostas rejeitadas pelos representantes do sindicato nas mesas de negociação. Na tentativa de suprimir as propostas governamentais que retiravam direitos dos professores foi preciso que os mesmos entrassem em greve várias vezes.

Nesse sentido, ficou evidente que se tratava de um governo que tentava conciliar, no comando da gestão, integrantes dos movimentos de esquerda com representantes das classes dominantes, os denominados progressistas, que se dispuseram a compor a gestão de um governo de esquerda, e adversos à história da luta da classe trabalhadora. Nesse sentido, concluímos que foi um governo ligado a setores progressistas e burgueses e primava pela participação popular e não à "organização dos mais excluídos. Essa é uma característica de um governo de Frente Popular" (LUZ, 2008, p. 179).

Tendo em vista efetivar na prática o que foi estabelecido pelo PCCR/2010, o Sindicato dos Trabalhadores em Educação Pública no Pará (SINTEPP) continua lutando pela aprovação de um Plano de Carreira unificado, que atenda não somente aos docentes e especialistas, mas a todos os profissionais da educação pública estadual.

Enfim, para que se possa ter a garantia de políticas de valorização da educação pública é fundamental que os profissionais do ensino continuem se mobilizando para que os direitos da categoria não sejam negligenciados e negados pelo poder público.

\section{Referências}

ABREU, Mariza. Carreira do Professor. Agosto de 2011.Mimeo.

BRASIL. Constituição da República Federativa do Brasil. Brasília, DF: Senado, 1988. 
. Lei 9.394/96, de 20 de Dezembro de 1996. Estabelece as diretrizes e bases da Educação Nacional. In: BRASIL. LDB: Lei de Diretrizes e Bases da Educação Nacional: Lei 9.394/1996 - Rio de Janeiro: Lamparina, 2008.

Lei 9.424/96, de 24 de Dezembro de 1996. Dispõe sobre o Fundo de Manutenção e Desenvolvimento do Ensino Fundamental e de Valorização do Magistério, na forma prevista no art. 60, § 70, do Ato das Disposições Constitucionais Transitórias, e dá outras providências. Brasília, 1996.

. Ministério da Educação. Resolução 03, de 08 de Outubro de 1997, da Câmara de Educação Básica, do Conselho Nacional de Educação. Fixa Diretrizes para novos Plano de Carreira e Remuneração para o Magistério Público dos Estados, do Distrito Federal e dos Municípios. Brasília/DF, 1997.

. Lei n. 11.494, de 20 de junho de 2007. Regulamenta o Fundo de Manutenção e Desenvolvimento da Educação Básica e de Valorização dos Profissionais da Educação - FUNDEB, de que trata o art. 60 do Ato das Disposições Constitucionais Transitórias; altera a Lei n. 10.195, de 14 de fevereiro de 2001; revoga dispositivos das Leis n. 9.424, de 24 de dezembro de 1996, 10.880, de 9 de junho de 2004, e 10.845, de 5 de março de 2004; e dá outras providências. Diário Oficial da União, Brasília, DF, 21 jun. 2007.

. Lei n. 11.738, de 16 de julho de 2008. Regulamenta o Piso Salarial Profissional Nacional para os profissionais da Educação Básica Pública. Diário Oficial da União, Brasília, DF, 17 jul 2008.

. Lei no Lei no 13.005, 25 de junho de 2014. Aprova o Plano nacional de Educação (PNE 2014-2024) e dá outras providências. Diário Oficial da União, Brasília, DF., 26 de junho de 2014.

. Ministério da Educação. Resolução CNE/CEB n. 02/2009, de 28 de maio de 2009. Fixa as Diretrizes Nacionais para os Planos de Carreira e Remuneração dos Profissionais do Magistério da Educação Básica Pública. Diário Oficial da União, Brasília, DF, 29 maio 2009.

BRELAZ, Walmir Moura. PCCR dos Profissionais da Educação pública do Pará: Lei nº. 7.442. de 02 de Junho de 2010 - Comentado. Belém: SINTEPP, 2010. 
DUTRA JR, Adhemar F. (et al). Plano de Carreira do Magistério Público: LDB, FUNDEF, Diretrizes Nacionais e Nova Concepção de Carreira. FUNDESCOLA/MEC. Brasília, 2000.

FERREIRA, Denielson Moura. Mudanças e Permanências na Carreira do Magistério Estadual do Pará: 1986-2010. Dissertação (Mestrado em Educação) - Universidade Federal do Pará, Belém, 2016.

LUZ, Sílvia Letícia D’Oliveira da. A Valorização do profissional da educação e a carreira docente: A experiência do Governo de Frente Popular em Belém do Pará, 2008. Dissertação (Mestrado em Educação). Universidade Federal do Pará - Belém, 2008.

COELHO, Maria do Socorro da Costa (Org). A Estrela de Várias Pontas: o debate inicial sobre as políticas sociais no Pará. Belém: Paka-Tatu, 2009.

PARÁ (Estado). Proposta do governo sobre o Plano de Cargos, Carreira e Remuneração do Magistério Público da educação básica da rede pública de ensino do Estado do Pará e dá outras providências. 26 de Abril de 2010. 2010b.

. Lei no 5.351, de 21 de Novembro de 1986. Dispõe sobre o Estatuto do Magistério Público do Estado do Pará.

. Lei Estadual no 5.810, de 24 de Janeiro de 1994 - Regime Jurídico Único dos Servidores Públicos Civis do Estado do Pará.

Lei 7.442, de 2 de Julho de 2010. Prova o Plano de Cargos, Carreira e Remuneração - PCCR dos Profissionais da Educação Pública do Pará.

ROCHA, Maria da Consolação. Políticas de Valorização do Magistério: remuneração, plano de carreira, condições de trabalho - uma análise da experiência de Belo Horizonte. Tese (Doutorado em Educação) Faculdade de Educação da Universidade de São Paulo, São Paulo, 2009.

SINTEPP. SINDICATO DOS TRABALHADORES EM EDUCAÇÃO PÚBLICA NO ESTADO DO PARÁ. Proposta de Plano de Cargos, Carreira e Remuneração dos Trabalhadores da Educação Básica da rede pública de ensino do estado do Pará e da outras providências. Pará: SINTEPP, 2009. 
. SINDICATO DOS TRABALHADORES EM EDUCAÇÃO PÚBLICA NO ESTADO DO PARÁ. Cartilha comparativa entre a proposta do governo e a proposta do SINTEPP sobre o PCCR. Pará: SINTEPP, 2010.

Recebido em: outubro/2016

Aprovado em: dezembro/2016 